Article

\title{
Present Teaching Stories as Re-Membering the Humanities
}

\section{Vicky Gunn}

Learning and Teaching Centre, University of Glasgow, Glasgow G12 8QQ, UK;

E-Mail: victoria.gunn@glasgow.ac.uk

Received: 9 April 2014; in revised form: 19 June 2014 / Accepted: 19 June 2014 /

Published: 25 June 2014

\begin{abstract}
The ways in which Humanities scholars talk about teaching tell something about how we interact with the past of our own discipline as well as anticipate our students' futures. In this we express collective memories as truths of learning and teaching. As cultural artifacts of our present, such stories are worthy of excavation for what they imply about ourselves as well as messages they pass onto our successors. This paper outlines "collective re-membering" as one way to understand these stories, particularly as they present in qualitative interviews commonly being used to research higher education practice in the Humanities. It defines such collective re-membering through an interweaving of Halbwachs, Ricoeur, Wertsch and Bakhtin. It proposes that a dialogic reading between this understanding of collective re-membering and qualitative data-sets enables us to both access our discursive tendencies within the Humanities and understand the impact they might have on student engagement with our disciplines, noting that when discussing learning and teaching, we engage in collectively influenced myth-making and hagiography. The paper finishes by positing that the Humanities need to change their orientation from generating myths and pious teaching sagas towards the complex and ultimately more intellectually satisfying, articulation of learning and teaching parables. ${ }^{1}$
\end{abstract}

Keywords: Humanities; qualitative research; research-teaching linkages; graduate attributes; collective memory

1 This paper came together after I delivered a keynote presentation at the Higher Education Academy’s 2nd Annual Arts \& Humanities Learning and Teaching Conference: Storyville: Exploring narratives of learning and teaching. I aim to capture the tone of this keynote's "performance” in order to catch the spirit as well as the content of its delivery. 


\section{Prologue: Tales of Belonging or Alienation?}

"It is not easy to describe the distinctive nature of scholarship in Humanities. We do collaborate all the time, of course; it's just that most of our collaborators are dead.” ([1], p. 149).

And so the tall tale is told: An exaggerated, humorous, if short, narrative with which I can identify. It is alluring, draws laughter from slight embarrassment, helps me feel part of a community which accepts I spent a decade of my intellectual life in relationship with Bede (died CE 735). In short, through the sharing of a narrative with which I can identify, I am welcomed into a broader set of relationships. As Sally Munt suggests: "when people find themselves in a narrative, this is a momentary identification which is perceived as instrumental: a process of recognition occurs which functions through relationality to place the subject in a web of identification with subjects more like herself.” ([2], p. 5). Stories connect us; offer virtual and material intimacies; are the 'substance' of generations within the same, self-identifying, community (adapted from [3], p. 25).

Yet, simultaneously, the sentences above create and make public imaginary limits on how the Humanities seem to understand themselves. They enclose the nature of our collaboration in a rhetoric of uniqueness (uniquely indescribable but somehow linked to an interaction with the dead), cultivating boundaries of inclusion and exclusion. For some, the story becomes a tale of happy-ever-after and, for others, it becomes a bête noire. After all, the story conveyed above, if viewed in dramatic terms, could be read as the tale of the necromancer: the 'dead text' is the focus of our epistemological desires rather than humanity. Anxiety about this, for example, is writ large in Mikhail Epstein's manifesto on the transformative Humanities [4]. But what if you prefer a story in which the interactive creativity of the Humanities is better described as flying with dragons than sleeping with the dead?

From the outset, we need to remember two vital and simultaneous aspects to tales: they can function personally to ameliorate loneliness (allowing me to recognize others like me and assume a broader accord) and socially (communicating boundaries to be traversed by those who are not-yet-like me). The idea that 'narrative is ontological' (Munt [2], p. 5), means Humanities' scholars must address the question of whether our daily communications, including those about how, what, and why we teach, invite students to come into communion with us or act to exclude. Our tall tales have an impact. If Munt is right and stories allow for identification with and recognition of one another, which in turn results in a coherent web or network, our stories (and not just our practices) about learning and teaching have the capacity to foster both belonging and alienation. As such those of us dwelling in history, classics, literature, philosophy, theology have an ethical responsibility to analyse them and consider their possible effect on our students' learning (as well as the conceptual construction of our disciplines).

\section{Introduction}

Debates about what the Humanities are for and what it is they should teach and foster in universities seem to have become ubiquitous in the last decade [1,4-7]. From this has come a burgeoning literature expressing why the Humanities "matter" [8-10]. Maintaining a legitimate sense of place within universities at the same time as responding to transformations in both our research processes and 
teaching environments has created, in some, a sense of crisis. For others, however, it presents an opportunity to revisit the material world within the Humanities [11] as well as the space for propagating new genres and disciplines ([4], p. 290), and reforming the undergraduate curriculum [12,13]. In responding to the identification of where enhancement to learning and teaching needs to occur if we are to attend effectively to the, "why the Humanities matter" agendas, it has provided fertile fields from which to harvest swathes of qualitative data (See $[14,15]$ as examples of this). This is perhaps particularly true of those of us who work in the advancement of higher education but are still embedded/wedded to our work in the Humanities' disciplines in the traditional sense. For all, a perception of crisis, or at least the need to change, drives an underlying sense of urgency.

In the abounding discussion stories about learning and teaching are told and some of these tales provide the basis of this paper's orientation. I start from a pragmatic place: Stories about what a Humanities education is for and why it matters emerge as much informally and locally in conversations as much as globally through publications: how do these stories impact subsequently on our students perceptions of what being in the Humanities means in terms of imagining the discipline and studying within it? How might these students come to work for themselves and for the good of the Humanities from their understanding of these stories? Arguably, the implied cues in our discussions function as part of the inter-subjective canon of disciplinary socialization. They are an aspect of the day-to-day level of organizational cultures and as such play into the "technologies of the self", conducting personal adoption and incorporation of certain narratives so that membership can be felt and shown. This is not to deny student agency (through rejection or transformation of the stories) or to reify the idea that we are the dominating force in their undergraduate lives (and thus that they inherit our stories because of that dominance), rather it is to point out the potential of our stories to have unintended directional power via relational networks. What is inferred from our stories open and close avenues of academic pursuit and consequently influence degrees of engagement and inclusion. As such, where our students' learning is concerned, we evade their symbolic power at our peril.

The question is, of course, how do we construct a convincing interpretation to critique our own discursive tendencies and their apparently panoptic powers? To date, higher educational studies on such tendencies rely heavily on inductive research methods primarily dependent on qualitative interviews without exploiting any Humanities' theoretical paradigms at the coding and analysis stage. As such a trick is being missed: as 'insider researchers' of our own practice, Humanities theories have much to offer in terms of helping us to understand ourselves as much as our texts. This is not to refute the importance of qualitative data as an intellectually fecund resource (and indeed two such data-sets will be referred to here because of what they can illustrate $[14,15])$. Rather what is stressed here is that to gain more robust pictures of what might be happening, where disciplinary contexts have themselves produced theories about how cultures operate, it is effective to bring them into dialogue with inductive methods focused on capturing our experience as academic teachers in the Humanities.

From this place, the pivot of the article is: An underused but effective heuristic tool for accessing how our university-based stories about pedagogical instruction are both composed locally and function socially is collective re-membering (both the notion of and mechanisms behind how memories can be social, collective, delineated spatially, and replayed outside of their original time-space frames) and the theorizing underpinning it. We should embrace it as such when trying to understand present 
disciplinary conversations about learning and teaching, as well as how cues taken from them might impact on our students' futures.

\section{Method and Outline}

To create a structure from which to explore how we might come to say the things we do in qualitative interviews (arguably the artifacts of such conversations) and what, in turn, might be inferred from the content of such narratives, I concentrated specifically on writings about collective memory: Recruited for the key protagonists were: Maurice Halbwach's, The Collective Memory (1980), On Collective Memory (1992) [16,17]. Added to these were cameo but relevant roles to be played by components of Paul Ricoeur's, Memory, History, Forgetting (2004), James Wertsch's (2002) concept of collective remembering and Bakhtinian (Bakhtin, 1986) notions of speech genres [18-20]. The method which unfolded symbolizes a promiscuous polymathery on my part and, from the outset, I acknowledge that liberties may have been taken with the scholarship of others to create an interpretative framework. Structured interdisciplinary reading inevitably transfigures the material on which it has drawn. Consequently, for specialists in the original canons, its results often seem lacking in rigour and thus intellectually irritating. However, the emphasis in this paper is on the transformation of the components into a slightly different whole through their interweaving. To explore the implications of these interwoven readings, what follows is divided into the following sections:

- A theoretical methodology that draws together: the nature of our qualitative data around learning and teaching, the concept of collective memory, evidence of the limited geography in which we come to construct narratives about pedagogy and instruction, and the potential to identify particular speech genres within the data-sets. This means that to understand how our stories are constructed we need to combine the social theorizing of Halbwachs and Ricoeur, with the anthropological observations of Wertsch, and Bakhtin's concept of speech genres. In the interpretative dialogue between these works, four closely mingled assumptions about what might be present in qualitative data related to learning and teaching emerges: Firstly, stories of significance (even if apparently mundane) are recalled in interviews; secondly, we re-member (recollect, recognize ourselves and others, and re-materialize) the teaching context when we reflect on what we consider to be important about the links between teaching and learning in such interviews; thirdly, re-membering involves not only our individually separable perceptions and experiences but, via the process of recall, also the framing of them through an interaction with a culturally shared repertoire of concerns, sentiments, and problem-solving approaches that link us to our disciplinary predecessors as well as current colleagues; fourthly, and consequently, that the concept of collective re-membering, predicated on the "irreducible tension between active agent and cultural tool” [19,21], is a pragmatically useful interpretative device when considering our findings. As a result of such a theoretical methodology, it is asserted that the phrase collective re-membering is of more use than collective memory when we consider our present teaching stories.

- Two short case studies which illustrate the implications of the theoretical methodology when exploring the types of stories Humanities' lecturers seem to build and maintain in conversations about aspects of their teaching: Firstly, myths about transformational reciprocity in our discussion of research-teaching linkages and, secondly, saints' lives or sagas of inattention and suspicion 
around institutional-level educational agendas such as employability and global citizenship (particularly referred to collectively in the UK and Australia under the rubric of "graduate attributes' agendas”). These examples present story categories that emerged whilst I undertook two qualitative research projects around how research-teaching linkages and graduate attributes respectively currently operated within the Humanities $[14,15]$ and a brief reference to each of the data-sets introduces the case studies purely to establish the scene. Whilst by no means the fulcrum of this paper, the gathering and interpretation of these projects' related data represent the back-story of the more theoretical discussion outlined here.

- A final section raising the question of whether we erect and excavate simultaneously the wrong stories in our current designs of qualitative research when studying learning and teaching. This section concludes that it would be better to cultivate different types of narratives within the research process (particularly those being used by lecturers in the disciplines to understand teaching practices). If we want to capture the nuances of our experience as academic teachers of the Humanities, we actually need to shift the narratives/narrative resources on which we have come to depend when talking about learning and teaching.

In the spirit of storytelling and deliberate playfulness that lay behind this article's first outing as a conference keynote, I have also pressed Herodotus into service to provide illuminating metaphors. I have thus co-opted his description of Babylonian customs to emphasize or elucidate points. I ask my readers, therefore, to imagine they are travelling along the Euphrates to Babylon, where a river of interpretation runs through a city built from the fired bricks of primary and secondary sources.

\section{Theoretical Methodology: Unravelling the Narrative}

\subsection{Plot 1: Excavating the Emic Foundations of Our Stories: Bringing Qualitative Data together with the Concept of Collective Memory}

Forms of qualitative inquiry, with narrative at their heart, dominate the higher education (HE) learning and teaching landscape. The prominence of the single, semi-structured interview is embedded across the journals which deal with higher education practice-based research. In particular, over the last decade, a significant amount of emic material has been recorded and analyzed in terms of the outcomes of research-teaching linkages across Anglophone and European universities [22]. The Humanities have certainly not been immune to this trend [14,23]. Through our conversations with and as educational developers and researchers we have arguably been reflecting back local customs, meanings, and beliefs, rather than illustrating our material practices and how these might be contradictory or dissonant to our narratives about those practices [24]. These conversations are only concerned with communicating the meanings we ascribe to our actions, harmonizing ideal and experience and giving only one side of an insider's view [25]. Through them we tell our stories.

Additionally, the ascription of meaning is part of the constant dialogue between individual memory and the socio-cultural tools which help in its formation. As Ricoeur observes, "it is essentially along the path of recollection and recognition that we encounter the memories of others" ([18], p. 120). Our stories tell of how we make meaning of teaching situations and in so doing generate recollection, recognition, and thus to a certain extent re-materialization through conversation. Our recall of such 
stories in interviews is thus in part informed by collective (and in this case, often disciplinary) memories. With regard to making meaning of current learning and teaching situations and what we value as important, this suggests the possibility of uncovering a shared repertoire of concerns, sentiments, disciplinary morality, and phraseology that links our narratives to the past. In effect, it suggests a Halbwachs-like underlying mechanism operating between our contemporary experience and that of our disciplinary predecessors. Thus, what we say in qualitative interviews is a location not only for the excavation of our individual story but also the collective re-membering retained in the story. Our transcripts hint at the past beyond our immediate experience, expanding the time-frame in which the story was generated. (Reflecting on Halbwachs, Ricoeur refers to this as a widening of the temporal horizon of younger generations, [18], p. 394).

\subsection{Plot 2: Discovering that Collective Memories are Constructed in the Public Square}

If collective re-membering fashions our stories into a form of archaeological artifact, we need to excavate the factors involved in the propagation of a commonly shared repertoire that links the contemporary generation of disciplinary academics to the past. Here, Herodotus can help. When describing Babylonian customs, Herodotus notes that the sick do not consult physicians but rather, if someone is ill, they are laid in the public square and if the passers-by have had a similar ailment or know someone themselves who has had the disease, they: "give him advice, recommending him to do whatever they found good in their own case, or in a case known to them.” (Herodotus, Histories, 1:197). We have a similar process when it comes to learning about how to resolve issues in teaching. Studies make it quite clear that when we have a problem-solving situation in our classrooms, we are highly likely to prefer the example or advice of an associate to abstract theory or empirical findings ([26], p. 116).

Like the Babylonians, when it comes to teaching, rather than going for a robust evidence-base, Humanities academics enter the disciplinary public square to see how colleagues made meaning out of an apparently similar situation. In this we encounter a context where how we remember the circumstances and what is important to value is directly influenced by the "interruption" of our colleagues. In turn, those colleagues may well be recalling what they heard previously. This process is similar, then, to Halbwach's notion that collective memories are "recalled to us through others even though only we were participants in the events" ([16], p. 23). We have the original experience, but in discussion with others, there is the potential for a collectively influenced reframing. How we make sense of the circumstances becomes entwined with the register of sense-making of our predecessors as well as our contemporaries.

\subsection{Plot 3: Finding the Public Square Turned into a Disciplinary Gated-Community}

The prologue noted how stories can function to invite in or exclude those who encounter them, which raises the question of whether our collective re-membering operates in such a way that the public square conversations increasingly occur within a virtual fence, one that includes and excludes. The work on significant conversational networks about learning and teaching analyzed in Roxä and Märtensson [27,28] demonstrates how the bulk of conversational "passers-by" in the public square are drawn from our immediate disciplinary circle. The resultant network is based on trust, privacy, and 
shared intellectual problem-solving regarding teaching. What this means is, we have a clique to whom and from whom we construct our understanding of teaching. Our insularity can turn the public square into a virtually gated community.

Given that collective culture will orchestrate forgetting as well as re-membering, the skewing of our meaning-making towards a dominant or authoritative narrative within it becomes more probable [29,30]. This is not to deny the role of contestation and mediation within the process, which Halbwachs failed to address ([30], p. 379) and is increasingly the focus of debate [19]. Instead, it is to indicate the possibility of repetitions across generations that would result in a shared repertoire (sometimes regardless of changes to the material circumstances) because of the apparent legitimacy and authority associated with collective memories.

Recognizing this is important because, if Boyer and Wertsch ([31], p. 113) are right, the cultural "tools" represented in such repetitions express a particular agenda or goal (an implicit plot perhaps) without seeking recourse to explicit standards of veracity (as is witnessed when our discourse slips into nostalgia, for example). Indeed, if we examine what our qualitative data-sets suggest about our agendas related to the links between research, teaching and graduate attributes, what is exhibited maps onto evidence of how collective re-memories function, including:

(1) Toleration of distortion (such as inconsistencies between espoused over-all beliefs about learning and teaching and the narrative resources used to illustrate what we mean);

(2) Smoothing over of paradoxes;

(3) Inattention to omissions. In re-narration, for example, problematic and ambiguous content is often omitted ([32], p. 15). For Halbwachs this is one of the ways we deal with "inconvenient memories" ([17], p. 50);

(4) Assimilation of our senior colleagues' memories. This may "widen our temporal horizon”, giving us access to practical wisdom evolved over time, but it might also imprison the conversations in a passive persistence of first impressions ([18], pp. 394, 427), circumscribing criticality and consequential expertise acquisition;

(5) Amalgamation of phantoms which allow our immediate past to be linked to decontextualised beliefs about disciplinary predecessors we have not known. These phantoms often help locate our identity in a more positive history of the discipline. This process, in turn, can lapse into nostalgia and stereotyping, suppressing negative aspects of the longer past in the service of the kind of people we are or assume ourselves to be (see: [21]). These phantoms, in effect, enable us to engage historical representations to provoke and solidify particular identity-oriented affect and meaning (see: [33], p. 16). In this such phantoms lead to:

(6) Provision of forms of moral regulation.

In the process of translating practical wisdom from one situation to another, the plot may be subtly driven by established frameworks so that sight of the need to be creative is lost. Moreover, the translations cultivate a portfolio of narratives that exclude those who fail to accept the incorporated distortions, impressions, phantoms, and moral regulation. 


\subsection{Plot 4: Inviting Bakhtin to Reflect on Babylon’s Gated Community}

A consequence of the observations above is the direct relationship between collective re-membering and, to use Wertsch's phrase, narrative resources, which assist in shaping the way we think and speak about issues in teaching ([21], p. 120). Simply put, within our interview transcripts we have evidence of a qualitatively identifiable academic discourse genre which incorporates such narrative resources. This discourse genre occurs in the liminal space between primary speech genres (as defined by [20], pp. 60-62) and secondary discourse genres (of particular relevance here is the secondary literature produced about the nature of a given discipline that could be characterized as manifesto-like: ([20], p. 62; [34]). This liminal discourse genre, articulated in the light of work by Hengst and Miller, Maingueneau and Hyland [34-37], is discussed more fully elsewhere ([38], pp. 75-77). In short, however, it:

- Represents a phase before formalization;

- Relates to how the speaker brings their Self into play with their discipline;

- Captures cultural and moral themes;

- Is developed in a relatively unmediated communion within specific significant networks in the disciplinary teaching arena and consequently is generative of a gated community.

More specifically, these liminal discourses absorb academic desires and values which in turn can be transferred through interpersonal reception. How students engage with them explicitly relates to the key point of this paper: stories can appear to be invitations "in" or seem to reject and as such, we need to understand what they look like and how they seem to operate amongst the student body if we are to really come to grips with student disciplinary development.

\subsection{A Little Comment on Method Used}

If there are inherent connections between such a liminal discourse genre and collective re-membering, relevant narrative forms generated through communication processes are worthy of critique. In terms of relevance to this paper's subsequent focus on the types of stories which represent narrative forms of collective re-membering, the important point to note is: such a genre plays a role in both reflecting back primary speech genres and generating forward the more formalized texts identified as part of secondary speech genres (e.g., manifestos). Effectively, this is a dialogic process in which the local gets projected outwards and the global reflected back inwards. It is because of this process that, when we come to look at the story types, secondary texts relating to arguments about the nature of the Humanities are compared with the interview data.

With all these interwoven ideas in mind, the key question becomes: what in our story types suggests the embedding of collective re-membering and its attendant sense of recognition and identification? Ideally, we should be able to observe shared concerns, sentiments, disciplinary morality and even phraseology. There may also be a hint of an extended time-frame, suggestive of the incorporation of our predecessors' experiences. In terms of excavation, our interpretation is underpinned by an understanding that there was an original impulse behind the development of such collective re-membering, an original need that generated a way of dealing with or justifying a particular situation which subsequently became a fixed conversational object. Arguably, a dissonance between this fixed 
object and associated explanations might hint at an artifact of collective re-membering and thus should be the target of critical attention (otherwise we might indeed be caught in the passive persistence of first impressions). The two case studies below attempt to illustrate this and also suggest why being aware of such story types is of importance for our students' engagement with our disciplines. The first case study draws together insights from a qualitative research project based on 7 semi-structured interviews from the Humanities in Scottish universities [14]. The 7 interviewees were two Historians, one Classicist, one Philosopher, two Theologians and one person from Film and TV Studies. The second case study reflects on 5 semi-structured interviews, one each from Classics, English Literature, Theology and two from Celtic Studies, all at one research-intensive institution in Scotland [15]. Both case studies explore particular propensities in the qualitative data sets as well as the secondary literature on the nature of our disciplines: a leaning towards myth-making in terms of the pedagogy of the Humanities being intrinsically reciprocal and an inclination to saga-making with respect to educational agendas that we associate with any emphasis on the utility of higher education.

\section{Case study 1: Myths about Transformational Reciprocity in Our Discussion of Research-Teaching Links-Playing like Vampires?}

The first of the liminal discourse genres to illustrate are teaching myths. A key story we retell in the literature to describe the nature of our scholarship suggests that the link between research and teaching is based on a fundamentally transformational process which is a "multi-dimensional, mind-altering experience" rather than a vocational one ([39], p. 10) and is achieved through conversational/dialogic reciprocity. I found a similar assumption present in the transcripts that I gathered as part of the 2008-2009 Research-Teaching Linkages project [14]. As one of my interviewees summed up: “on the Arts side of the university we are not engaged in vocational training. We are engaged in developing multi-sided people who can engage with a whole range of different problems and techniques such as information retrieval, constructive engagement/critical engagement with information, sifting information and also making judgments on the basis of the past or past experience." (Historian).

In bringing that data-set together with the secondary discourse genres, it became clear that reciprocal conversation is behind this development and occurs between three inter-linked groups: our texts, our colleagues and our students (not necessarily in that order of importance).

\subsection{Reciprocity with Our Texts: When does Collaboration with the Dead Become Necromancy?}

From the outset I noted the extent to which it is possible to identify with Collini's notion that our scholarship has a relational element with those who died generations and centuries ago. Additionally, anyone who has spent time reading, contemplating and changing their ideas about disciplinary canons in the light of Gadamer [40], will argue (and I am one of these people) that interpretative hermeneutics related to how we read our texts, also change how we read ourselves, which in turn affects the direction of our lives. Add to this our engagement of students in the process and there is clearly the potential for a triangular collaboration of present-day minds, historical intellectual activity, and creativity. Yet, as Epstein notes, in our focus on our texts, have we turned away from humans? Have, "to a certain extent, the Humanities stopped being human studies and become textual studies, ...criticism rather than creativity and suspicion rather than imagination?” [4]. If this is the case, do our 
claims to a holistic rather than a purely textual hermeneutic approach reflect a collective re-membering more than a present-day actuality? What is clear is that the Humanities are developing students' ability to make qualitative judgements about the type and nature of information, what is much less clear is how this is turned to questions about humanity. We are not quite necromancers, yet, in our fixation with creating analytical frameworks to think originally about our texts and the curation and categorisation of the canon of our disciplines inherent in this, have we been led away from bigger humanistic questions? Have we become so centred on original ways of thinking about the text that questions of human being and doing are side-lined in our teaching?

\subsection{Reciprocity with Colleagues: Back to the Gated Community in Babylon}

I admit that this was not a particular feature of the interviews I undertook, but is a common thread in current debates about managerialism and the loss of collegiality across the Humanities [41]. I think there is another aspect of the Humanities myth lurking in this discussion and we need to ask ourselves: what do we really mean by collegiality in the Humanities? Perhaps we actually just use "collegiality" as an antonym for corporate purpose ([42], p. 78) rather than as a description of the quality of our relationships. How for that matter are polymaths collegial? In terms of the notion of gated community mentioned earlier, the key point to acknowledge is that our peer-based social networks operate through hierarchies of status [28]. This means that dominant and subordinate cultural tools play out dependent on the systems we use to legitimate them (and the value we place in those systems). We need to be far more critical about our claims to collegiality as they, more than other stories here, relate to collective re-membering that not only accepts distorted pictures of the present but also passes on distortions from the past.

\subsection{Reciprocity with Students (2008-2009 Data-Set): Mutual Metamorphosis or Thought-Vampirism?}

The reciprocal and often transformative relationship of mutual conversation between participants in disciplinary exploration is a central myth of the Humanities identity. In our secondary discourse genres, the dialogue between students and staff which moves our disciplines forward is typically described as being dependent on novices as much as experts. In all of this, dialogue is an inter-dependent, balanced, shared process, where students and staff play equally important, if different, roles. The novices bring fresh eyes [43], freed from the universalizing effects of socialization into disciplinary norms. In this, the conversation between staff and students is an interwoven web between research and teaching (Jan Parker is a particular proponent of this sense of mutuality ([44], p. 23), but see also: $[45,46])$. Indeed, an extension to this perspective sees students as the subversives upon which critical reinterpretation is reliant, because they are not so dependent on established disciplinary paradigms [43].

On reflection, however, how this reciprocity manifests is unclear. Indeed, it was the lack of clarity around this notion of reciprocity in the research-teaching linkages data-set that first started me wondering about how collective influence with a past as well as in the present might be playing out within the Humanities. When discussing the pedagogic environments in which dialogue occurs, the academics divided into two groups: 
- Those who perceived the importance of dialogue but who teach in more didactic manner/learning environments; (Historian; Classicist);

- Those who perceive the importance of dialogue and use learning environments most likely to foster interaction between themselves and the students; (Both Theologians).

In this apparent dichotomy one would perhaps consider the second group as most congruently aligned with respect to dialogic belief and practice. Yet, the same academics' views of the student members in the dialogue as participants in the research process evoked common themes that did not consistently overlap with the perceptions of the pedagogic environment. Thus:

- Students were fully participatory and informed the final research product of an individual lecturer. As the philosopher commented: "I see all the lectures as conversations and I want to know what people think about the idea because they have fresh minds.” (Philosopher). One of the historians we interviewed also noted that his research-content-based teaching was still very much a two-way process, from which he benefitted, suggesting that he gained through, "Being challenged, students asking questions that are difficult and things that I hadn't thought of and would need to go and check out....” (Historian)

- The students were participatory because of the amount of their engagement with the subject, but they did not significantly influence the lecturer's research output (Film and Television Studies).

Additionally, the forms that the dialogue takes, as expressed by the interviewees, were rarely articulated as two-way conversations. Even where the lecturer stated explicitly that it is a two way process, probing elicited a range of strategies, most of which relate to the lecturer doing something for the students rather than the students working alongside the lecture:

(1) Empathy through expertise: (Classicist) "being a researcher...enables you to see what a first year student encountering a classical text for the first time will in fact need and actually that's the real research-teaching linkage at pre-honours level—-the idea that you are sufficiently far on in your grasp of the subject to be able to put yourself in the place of the person who is encountering it for the first time...” and help them unpack the subject through that understanding.

(2) Facilitating connections: (Theologian) “...we [the researcher] are also making new connections that aren't immediately apparent for the students...what I am seeking to do is to teach the students a process and use my own experience as a researcher/writer to make that available to the students...I'm really trying to make connections for the students....essentially what students are getting is my fresh thinking about how the whole area is developing..." (At the same time this Theologian clearly sees student process as more than just excitement: "it's [his teaching] very much on that model of personal engagement in the sense of not just engaging the student in being excited about the subject but the actual student's experience being a resource of authority and actually a data source...it's not just about mining a theological tradition".

(3) Setting the parameters of the discussion: "Oh the process [of research-led teaching] is two way. ...it's interesting because over the last couple of years I have talked to the consciousness class about the need for emotions [in the studies of consciousness]...it's a two way process, you tease ideas out together. I got much more out of the paper yesterday when I was talking to the students than I did when I was reading it by myself...” (Philosopher). 
What is clear from the interviews is that the myth of dialogue is an ideal with far more variable embodiments in practice and most of these embodiments suggest a misalignment between perception and practice. In the tall tales captured in my interviews with staff, fresh, unfettered minds clearly feed both our thinking and our publications. Such nurturing is at the heart of our originality. Yet, our shared narrative resources suggest a misalignment between:

- Firstly, the spoken importance of the dialogic relationship in which the novice is critical: lectures are conversations and we want to know about student thoughts because, "they have fresh minds”;

- Secondly, a narrative resource incorporating the sub-plot of the power of our own research interests to determine content and sometimes process. Thus, we make the connections not immediately apparent for the student, which means students are getting our "fresh thinking about how the whole area is developing...”.

- Thirdly, the implication, from the recalled direction of intellectual creativity, that it is less two-way mutuality and more uni-directionality, with us (and the disciplines we embody) being the beneficiaries. We might note that research-content teaching is still very much a two-way process but one, nonetheless, from which we benefit explicitly. Our gains come through being challenged and, through that challenge, "getting so much more out of our own reading”. So the students ignite our new understandings, but is this a shared process? And, perhaps more to the point, how do we show them that it is?

In terms of identifying an example of collective re-membering, what is evident here is an incongruence between reciprocity and our understanding of how students are involved in that relationship. In the hope of reciprocity we omit the common experience of delivering something to the students, but then reintroduce it as we try to explain how such reciprocity manifests. The critical question we need to ask, is from where did such a discourse emerge and why? I noted earlier that underneath collective re-membering may be a justification of a way of managing a situation that then becomes a fixed object. Arguably, the discourse of reciprocity has arisen out of perceived crises with the place of the Humanities in the university, particularly in this case the massification of higher education that has lead to an apparent de-interpersonalisation of Humanities' pedagogical approaches. What we are left with are the phantoms of concern and sentiment of reciprocity, but when we try to explain these we fall back into common phrases that indicate the importance of us as deliverers of ideas, with students" "freshness" providing a particular sense of what they bring to the disciplinary equation.

This then, is a collectively reinforced myth of metamorphosis induced through dialogue woven through a narrative from which we could infer that we "suck the fresh minds of the young" to maintain our intellectual fecundity. Our sub-plot hints that we might actually be vampires-of-thought rather than just half of mutual epistemological growth. What does this mean in terms of this paper's opening statements about how stories function? If this narrative is operating socially for our students as well as personally for us, how does it influence their learning behaviours? How does such a story interact with the practical realities of the classroom to cultivate a sense that, despite a myth of mutuality, originality in our disciplines emerges from the expert drawing on the students rather than through a more equal collaborative activity? Do our students think they need to become vampires to be original? This becomes even more problematic when we realize the moral value we place on originality, with the 
sense that its absence from someone's thinking is evidence of conformism, lazyness, and a lack of intellectual authenticity [47].

When discussing the ideas behind this keynote with a friend from Psychology, he pointed out that relationships can be experienced as personal and yet not be interactive [48]. If we perceive it personally, if it touches us, it has an essence of reciprocity, but this is not necessarily an essence others in apparent relationship with us feel. Our myth of research-teaching linkages as being jointly reciprocal, the fresh minds of novices, and the consequent generation of originality in our and the students' thinking is a story we relate to on a personal level, as are the notions of collegiality and collaboration with the text. These are storylines that reflect our inner world of hope, intent, and assumed affinity.

However, as social "instruments", the storylines simultaneously construct communication outwards, drawing from both one's personal psychology and also the collective when recalling how we achieve links between research and teaching. What seems to be expressed in our myth is an internal dialectic between shared recognition (leading to reciprocity), on the one hand, and self-assertion (leading to control and ownership), on the other [49]. Our myth captures and projects outwards an inevitable tension between the expert's need to be recognized at the same time as recognizing students' intellectual independence [50]. How this functions to constrain a sense of equality (and attendant social solidarity) is a key question in terms of student engagement and our hopeful narratives offer students a much less inclusive encounter with us than we, perhaps, realize.

\section{Case Study 2: Graduate Attributes, Saints' Lives or Sagas of Inattention and Suspicion- Anti-Neoliberal Ascetics?}

The second of the liminal discourse genres relevant here are those narratives which contain a peculiar mix of individual intellectual heroicism (as defined by the discipline and focused on originality) and hagiographical conventions. These pious teaching sagas (for want of a better name) seem to operate as ways of re-membering what makes our disciplinary views about what we should teach unique and quasi-essential. In effect, they enable us to define ourselves through particular virtues and, though not quite the abstinence fuelled rhetoric of the fourth century (CE) ascetic, they illustrate what we believe is necessary to renounce in the cause of the Humanities. There is, thus, an implied "purposeful lifestyle" incorporated into the sagas and we should at least be aware of the potential this has to influence student choices. These narratives are seductive in their simplicity, arranging disembodied, morally-laden tropes into texts about what it is or is not appropriate to favour.

When it comes to how these teaching sagas are expressed in the secondary literature, the hagiographical tropes tend to divide into three inter-dependent clusters: firstly, a continued reflection back to a monkish vocation, with the "culture of the West once again saved by ascetics” ([7], pp. 10, 42); secondly, an underlying assumption of the morally superior non-vocational as opposed to vocational [6]; and, thirdly, education for a social good rather than for profit [5]. Arguably, such tropes paradoxically obscure and materialize Humanities' cultural phantoms at the same time, particularly the ones that attempt to mark them out as being part of a unique vocation that should not be compromised through attachments to material advantages. Indeed, useful discussion of the genealogy of such phantoms can be found in ([8], pp. 59-88). Of course, the inconvenient memory omitted from this secondary genre is 
that academics in the Humanities are already tied into systems of material advantage: state, beyond-state, and increasingly student sponsored.

Where the pious sagas are manifested most strongly in that liminal space prior to expression in the secondary sources is in relation and often opposition to ideological agendas around employability, entrepreneurialism and, perhaps less obviously, global citizenship. How they play out in the dataset that I gathered on graduate attributes [15] is through a conversational rhetoric of vague inattention, suspicion and ambivalence. Phrases relating to entrepreneurialism and work-related learning often make it clear that it is (inattention) or should be (deliberate inattention born of suspicion) at the bottom of any taxonomy of attributes undergraduate students might be working towards in the Humanities. As the Classicist commented: “'Equipped for Global Citizenship?' I tend to be suspicious of anyway...how are we defining citizenship?... I would probably not take it much into consideration except to the extent that a bureaucrat was obliging me to. Even them I might try to simply frame other goals that I have in such a way as to appear to fulfill that requirement. I don't especially want students to be career aware, I tend to be relatively suspicious of that phrase.”

The acknowledgement behind this is that it just "doesn't seem to easily fit" or is not something explicitly being pursued (One of the academics from Celtic Studies noted: entrepreneurial is quite hard to fit into Celtic Studies straight off.”), though it emerges from knock-on effects of the students' studies (This Celtic Studies scholar went on to state: “entrepreneurial, global citizenship and ethically-minded - they're not things that I teach on a surface level or that I particularly encourage my students towards...I think they're kind of knock-on effects of what I'm doing but it's not something I am consciously striving for.”). Phrases relating to global citizenship portray it as a potentially worthy goal in some cases or just impossible to deliver in others. For the English literature scholar there was a sense that employability and entrepreneurialism where of importance but best developed through extra-curricular activities. Their reaction to Global citizenship was, however, unequivocal: “Global citizenship makes me feel slightly nauseous, just the term; I mean it's nonsense, we're not global citizens.” Interestingly, amongst the students I interviewed, there was a similar lack of perceived importance of entrepreneurial and work-related attribute development, but much more of a sense that being prepared to become ethically minded, global citizens was critical. If they had ideological concerns about employability they did not about global citizenship.

I propose that, for some academics, narratives of inattention and suspicion are converted into renunciation hagiographies which, in their turn, gain legitimacy through publication. This is not to deny the imperative of the Humanities to challenge and critique both ideological positions and compliance-oriented educational demands. Nor is it to valorize naivety. It is, instead, to reflect that the translation from suspicion to renunciation has the power to lead us away from responsibilities to our students and their futures. Yet these very responsibilities can only be effectively engaged with through the mechanisms valued by the Humanities: critical creativity, in depth textual analysis that allows us to anticipate possible and probable consequences for our futures, and imagination. Academics interviewed for my projects were not articulating particularly heroic tropes, more typically they were either expressing overt negativity or neutral non-engagement (except where they were already working within a more applied paradigm such as practical theology and archaeology). The critical issues for me in this are two-fold: 
(1) Suspicion, ambivalence and neutrality hint at a lack of responsibility for directing undergraduate experience beyond the gated communities. In a world of limited resources, deflecting responsibility and avoiding the real opportunities for creative engagement in problem-solving is becoming increasingly unsatisfactory if not downright unethical.

(2) By not engaging formally in the discussion about our students' broader futures, certain voices which claim to be authoritative in the Humanities get disproportionate cover about what we are doing and how we are doing it (See: [8], p. 63). This includes voices that make very Anglophone assumptions which fail to recognize the complexity of social, cultural, environmental, and economic needs across the globe.

Ultimately, critical, creative transformation in which imagination and thought are harnessed to solve as well as identify intellectual and practical challenges need not be dependent on stories that negate either the vocational or the material. But how can we tell and value new tales?

\section{Are We Excavating the Wrong Stories?}

I realize that the previous sections paint an overly pessimistic picture of our myths and sagas. This is, of course, a deliberate attempt to ferment debate. In the methods used, I have generated a noir tale all of its own. I want to clarify now what I have been hinting at all along: some of the shortcomings, at least in terms of the content and narrative resources of the stories, actually relate to how the stories come to be told. The method of qualitative interview upon which we have come to depend encourages an unbalanced privileging of myth and saga. These genres in their turn smooth over how we understand ourselves, harmonize the real-life paradoxes of learning in the Humanities, silence divergent views, and replay the past through all the foibles and avoidance of inconveniences that make up collective re-membering. The tales in the transcripts can become the collective memories. These stories may assist in the integration of fragments of experience into a coherent whole, but in their re-narration they incrementally change the plot of what we think we experienced. Having given these stories credibility and legitimacy through our reliance on the method (and the demands on us to publish the related outcomes), we are involved in a process of collective forgetting tied to constituting our secondary discourse genres. Myths and sagas are being reified.

What is needed now is a method that rebalances our narratives towards tales of paradox. In other words, we need a way of telling our stories so that conventions about learning and teaching are disrupted and dissonances brought to the foreground. This is already being recognized in teacher education [51]. From the work of scholars in theology and religious studies, moreover, we know that myth has a complementary narrative form, the parable. This is a form of story that challenges our preference for idealized worldviews and the related process of converting the mythic into a reality [52]. It has a brief, concentrated plot that troubles the reader, taking them beyond their comfort zone of understanding, to new insights [51]. Through a pattern of data collection which requires the articulation of parables about the links between research, teaching and broader attributes in the Humanities, we might establish a form of qualitative inquiry that captures more fully the nuances of our beliefs and practices. This would shift our focus from immediate recall and its associations with collective re-membering, to a more satisfying, complex, and ultimately authentic way of making sense of the power of learning and teaching in the Humanities. 


\section{Conclusions}

And thus our time together on this particular Babylonian plain draws to a conclusion. The Euphrates has been transfigured into a pathway of local personal memories interacting with the clay of collectively crafted brick remembrances. Comfortable myths and sagas unearthed from academic discourse are, however, as potentially exclusive as they are hopefully inclusive and their symbolic implications need to be exposed. In such a vein it is perhaps no surprise to find that Herodotus' description of Babylon is itself more folktale than accurate depiction. Yet generations of scholars pursued studies intending to assert his reliability, even as other forms of evidence emerged to demonstrate his limitations [53]. Beguiled by the harmonizing flourishes of the story, we can be seduced into considering it as the rather than $a$ truth.

The need to critically interrogate myths and sagas around learning and teaching, their emergence from our daily acts of speech and recall, and their connection with the place of the Humanities in the academy is important. Finding a method to do so is surely a Humanities' imperative, especially as the material worlds of scholarship, knowledge generation and curation change, but also given the increasing calls for us to reassert our role within the realm of human (as well as) textual studies. To assist in critiquing our own stories, we might need to draw on, metaphorically speaking, another Babylonian custom. With a certain degree of relish, Herodotus notes that, "at some point in her life every woman of the land is required to sit in the sanctuary of Aphrodite and have sex with a strange man" (Herodotus, Histories, 1:199). For us to really break the cycle of gated communities and reductive rather than expansive collective memories, we too might need to interact intimately (intellectually) with strangers, seeing the temple of Aphrodite as the edifice in which interdisciplinarity and interprofessionalism are fostered.

\section{Epilogue}

Stories invite in but can also repel. In so doing they generate networks of recognition and alienation. For me, learning and teaching in the Humanities is about soaring with dragons whilst teaching others to fly, rather than being a necromancing, vampire-of-thought under the tyranny of a suspicious mind. However, perhaps a parable would illustrate that flying with dragons and suspicion-fed, thought vampirism are both integral parts of an Humanities education, providing a paradoxical context from which we and our students can be cultivated to achieve great things.

\section{Acknowledgements}

I am indebted to my “critical writing friend”, Susan Carter of Auckland University, for editorial and motivational support. I am also grateful to the original conference organizers who, through their invitation, forced me to make coherent sense of niggling concerns around Humanities' teaching stories that I had been considering for too long without writing down. Additional thanks go to the students of the University of Glasgow's Doctorate in Practical Theology where I still teach, particularly to Gordon Kirkwood for pointing out to me the importance of parables in storytelling. The funding for the qualitative research mentioned here came from QAA Scotland as part of their Quality Enhancement Themes work. 


\section{Conflicts of Interest}

The author declares no conflict of interest.

\section{References}

1. Stefan Collini. What Are Universities for? London: Penguin, 2012.

2. Sally Munt. Heroic Desires: Lesbian Identity and Cultural Space. London: Cassell, 1998.

3. Leonard Webster, and Patricie Mertova. Using Narrative Inquiry as a Research Method: An Introduction to Using Critical Event Narrative Analysis on Teaching and Learning. Hoboken: Taylor and Francis, 2007.

4. Mikhail Epstein. The Transformative Humanities: A Manifesto. London: Bloomsbury, 2012.

5. Martha Nussbaum. Not for Profit: Why Democracy Needs the Humanities. Princeton: Princeton University Press, 2010.

6. Elizabeth Bullen, Simon Robb, and Jane Kenway. "'Creative destruction': Knowledge economic policy and the future of the arts and Humanities in the academy.” Journal of Education Policy 19 (2004): 3-22.

7. John Russo. The Future without a Past: The Humanities in a Technological Society. Columbia: University of Missouri Press, 2005.

8. Helen Small. The Value of the Humanities. Oxford: Oxford University Press, 2013.

9. Celia Chazelle, Simon Doubleday, Felice Lifshitz, and Amy Remensnyder. Why the Middle Ages Matter Medieval Light on Modern Injustice. London: Routledge, 2012.

10. Isabel Gil. “Monks, Managers and Celebrities: Refiguring the European university.” In Making the University Matter. Edited by Barbie Zelizer. London: Routledge, 2011, pp. 73-83.

11. Richard Sennett. The Craftsman. London: Penguin, 2009.

12. Vicky Gunn. "Constraints to implementing Learning Partnership Models and Self-Authorship in the Arts and Humanities.” In The University and its Disciplines: Teaching and Learning within and Beyond Disciplinary Boundaries. Edited by Carolin Kreber. Abingdon: Routledge, 2009, pp. 169-78.

13. Vicky Gunn. “Arts \& Humanities’ Undergraduate Dissertations: Regenerating Early Researcher Socialization for Diverse Futures (UK Perspectives).” In Supervising and Writing a Good Undergraduate Dissertation. Edited by Roisin Donnelly, John Dallat and Marian Fitzmaurice. Bussum, Netherlands: Bentham Science Publishers, 2013, pp. 149-86 [e-book].

14. Vicky Gunn, Steve Draper, and Mel McKendrick. Research-Teaching Linkages: Enhancing Graduate Attributes in the Arts, Humanities and Social Sciences. Glasgow: Quality Assurance Agency for Higher Education (Scotland), 2008. Available online: http://www.enhancementthemes.ac.uk/docs/publications/enhancing-graduate-attributes-artsHumanities-and-social-sciences.pdf?sfvrsn=14 (accessed on 10 June 2014).

15. Vicky Gunn, and Jamie Wightwick. "Final Report of the Graduate Attributes Working Group.” University of Glasgow, Glasgow, UK, 2010. Available online: http://www.gla.ac.uk/media/ media_218773_en.pdf (accessed on 10 June 2014).

16. Maurice Halbwachs. The Collective Memory. Translated by Francis Ditter and Vida Ditter. New York: Harper Colophon Books, 1980. 
17. Maurice Halbwachs. On Collective Memory. Edited and translated by Lewis Coser. Chicago: University of Chicago Press, 1992.

18. Paul Ricoeur. Memory, History, Forgetting. Translated by Kathleen Blamey and David Pellauer. Chicago: University of Chicago Press, 2004.

19. James Wertsch. Voices of Collective Remembering. Cambridge, UK: Cambridge University Press, 2002.

20. Mikhail Bakhtin. Speech Genres and Other Late Essays. Translated by Vern McGee. Austin: University of Texas Press, 1986.

21. James Wertsch. “Collective Memory.” In Memory and Mind in Culture. Edited by Pascal Boyer and James Wertsch. Cambridge, UK: Cambridge University Press, 2009, pp. 117-37.

22. Jan Schapper, and Susan Mayson. "Research-led teaching: Moving from a fractured engagement to a marriage of convenience.” Higher Education Research and Development 29 (2010): 641-51.

23. Gerda Visser-Wijnween. The Research-Teaching Nexus in the Humanities: Variations among Academics. Leiden: Mostert \& Van Onderen, 2009.

24. Alastair Ager, and Maryanne Loughry. "Psychology and humanitarian assistance." The Journal of Humanitarian Assistance, 1 April 2004. Available online: http://sites.tufts.edu/jha/archives/80 (accessed on 10 June 2014).

25. Anne Jones. "Generic attributes as espoused theory: The importance of context." Higher Education 58 (2009): 175-91.

26. Catherine Scott, and Steve Dinham. "Born not made: The nativist myth and teachers' thinking." Teacher Development 12 (2008): 115-24.

27. Torgni Roxä, and Katarina Märtensson. "Significant conversations and significant networksExploring the backstage teaching arena.” Studies in Higher Education 34 (2009): 547-59.

28. Torgni Roxä, Katarina Märtensson, and Matthias Alveteg. "Understanding \& influencing teaching and learning cultures at university: A network approach.” Higher Education 62 (2011): 99-111.

29. Paul Connerton. How Modernity Forgets. Cambridge, UK: Cambridge University Press, 2009.

30. Farhat Shahzad. “Collective Memories: A complex construction.” Memory Studies 5 (2011): 378-91.

31. Pascal Boyer, and James Wertsch, eds. Memory and Mind in Culture. Cambridge, UK: Cambridge University Press, 2009.

32. Harald Welzer. "Re-narration: How pasts change in conversational remembering." Memory Studies 3 (2010): 5-17.

33. Roger Simon. The Touch of the Past: Remembrance, Learning, and Ethics. New York: Palgrave Macmillan, 2005.

34. Dominique Maingueneau. “Analysis of an Academic Genre.” Discourse Studies 4 (2002): 319-42.

35. Julie Hengst, and Peggy Miller. "The heterogeneity of discourse genres: Implications for Development.” World Englishes 18 (1999): 325-42.

36. Dominique Maingueneau. "Literature and discourse analysis." Acta Linguistica Hafniensia 42 (2010): 147-58.

37. Ken Hyland. Academic Discourse. London: Continuum, 2009.

38. Vicky Gunn. "Mimetic desire and intersubjectivity in disciplinary cultures: Constraints or enablers to learning in higher education?” Studies in Continuing Education 36 (2014): 67-82. 
39. Tatiana Yarkova, and Aleh Cherp. "Managing the sacred? Perspectives on teaching excellence and learning outcomes from an international postgraduate university." European Journal of Higher Education 3 (2013): 24-39.

40. Hans Georg Gadamer. Truth and Method, 2nd rev. ed. Translated by Joel Weinsheimer and Donald G. Marshall. Albany: SUNY Press, 1989.

41. Cath Lambert, Andrew Parker, and Mike Neary. "Entrepreneurialism and critical pedagogy: Reinventing the Higher Education Curriculum.” Teaching in Higher Education 12 (2007): 525-37.

42. David Watson. The Question of Morale: Managing Happiness and Unhappiness in University Life. London: McGraw-Hill, 2009.

43. Catherine Cubbitt. "Images of Saint Peter: The Clergy and the Religious Life in Anglo-Saxon England.” In The Christian Tradition in Anglo-Saxon England: Approaches to Current Scholarship and Teaching. Edited by Paul Cavill. Cambridge, UK: Brewer, 2004, pp. 41-54.

44. Jan Parker. "Humanities Higher Education: New Models, New Challenges.” In Contemporary Themes in Humanities in Higher Education. Edited by Ellie Chambers. Dordrecht: Kluwer, 2001, pp. 21-43.

45. Mary Henkel. “Teaching and Research: The Idea of a Nexus.” Higher Education Management and Policy 16 (2004): 19-31.

46. Ben Knights. "Intelligence and Interrogation: The identity of the English student." Arts and Humanities in Higher Education 4 (2005): 43-61.

47. Joshua Guetzkow, Michèle Lamont, and Grégoire Mallard. "What is Originality in the Humanities and Social Sciences?” American Sociological Review 69 (2004): 190-212.

48. Steve Draper, University of Glasgow, personal communication, 2013.

49. Jessica Benjamin. "Beyond the Doer and Done to: An Intersubjective View of Thirdness." Psychoanalytic Quarterly 73 (2004): 5-46.

50. Barbara Schapiro. “Negotiating a Third Space in the Classroom.” Pedagogy: Critical Approaches to Teaching Literature, Language, Composition, and Culture 9 (2009): 423-39.

51. Robert Bullough. "Parables, Storytelling, and Teacher Education.” Journal of Teacher Education 61 (2010): 153-60. Available online: http://jte.sagepub.com/content/61/1-2/153.full.pdf+html (accessed on 10 June 2014).

52. Herbert Anderson, and Edward Foley. Mighty Stories, Dangerous Rituals: Weaving together the Human and the Divine. San Francisco: Jossey-Bass, 1998.

53. Wouter Henkelman, Amélie Kuhrt, Robert Rollinger, and Josef Wiesehöfer. "Herodotus and Babylon Reconsidered." In Herodot und das Persische Weltreich. Herodotus and the Persian Empire (Classica et Orientalia CLeO Band 3). Edited by Robert Rollinger, Brigitte Truschnegg and Reinhold Bichler. Wiesbaden: Harrassowitz Verlag, 2011, pp. 449-70.

(C) 2014 by the author; licensee MDPI, Basel, Switzerland. This article is an open access article distributed under the terms and conditions of the Creative Commons Attribution license (http://creativecommons.org/licenses/by/3.0/). 